\title{
Two minute walking distance in cystic fibrosis
}

\author{
C J UPTON, J C TYRRELL, AND E J HILLER \\ Department of Paediatrics, City Hospital, Nottingham
}

SUMMARY We have evaluated the 'two minute walking distance' in children with cystic fibrosis as an objective measurement of exercise tolerance. There was a strong correlation between walking distance and height in 89 normal children $(r=0 \cdot 72)$. Fifty children with cystic fibrosis showed a similar correlation $(\mathrm{r}=0.56)$ with a mean result of $94 \%$ of that expected for height compared with the normal children. There was a training effect in the normal children with the second walk being significantly better than the first, but this was not evident in children with cystic fibrosis. The test was reproducible with no significant change in 12 children retested after one to three months. Sixteen children with cystic fibrosis admitted for treatment of chest disease showed a significant improvement in walking distance with treatment. Children as young as 5 years old can perform a walking distance test. It seems to be an objective way of assessing exercise tolerance and can help in evaluating response to treatment.

It is often difficult to show objective improvement in the clinical condition of patients during inpatient treatment for exacerbations of chest disease in cystic fibrosis. This has become more of a problem with the development of an increasingly aggressive approach to management that necessitates the admission of children with pulmonary function closer to the normal range. Redding et $\mathrm{al}^{1}$ did show significant improvement in various measures of pulmonary function during inpatient treatment. These, however, were in children who clearly had poor lung function; peak expiratory flow rate (PEFR) was $30 \%$ of expected at admission, compared with $66 \%$ of that expected in the children admitted in our study. Cerny et $a l^{2}$ also reported improvement in lung function during periods in hospital and additionally looked at exercise tolerance. They used an exercise test on a cycle ergometer, however, and the patients were mainly teenagers and young adults. Such studies are often not possible with younger children, even if the equipment is available, and it is another consequence of more aggressive management that younger children require admission. Apart from a simple PEFR it is difficult for them to cooperate with lung function studies, let alone complicated exercise tests.

Although easy to carry out, peak flow testing does have drawbacks in assessing response to treatment, particularly in young children. PEFR varies during the day, and also in response to treatment such as bronchodilators and physiotherapy. Over a period of several days it is often difficult to correlate PEFRs done at different times and to draw appropriate conclusions. This short term variability also means it is not particularly useful in looking at changes in lung function over a period of years. We have also become aware that some children 'cheat' with a peak flow meter, accelerating flow in the mouth with the tongue, a phenomenon also reported in older patients. ${ }^{3}$

This led us to look into other ways of objectively assessing improvement in children with cystic fibrosis. We have assessed night time cough charts and daily sputum weights as well as simple tests of exercise tolerance. It has been shown that the 12 minute, ${ }^{4}$ and two and six minute ${ }^{5}$ walking distances are reproducible measurements of exercise tolerance in adult patients with chronic airways obstruction. In view of the short attention span of many young children, and the high reproducibility of the two minute walking distance, ${ }^{5}$ we decided to evaluate this test in our young patients with cystic fibrosis.

\section{Method}

Tests were carried out in an enclosed hospital corridor with no gradient along a 35 metre course marked at five metre intervals. Each child was asked to walk as fast as they found comfortable but not to run. Simple verbal encouragement was given at each turn. Walks of two minutes were timed by stopwatch 
and the distance covered measured by tape from the nearest five metre mark. In view of the known training effect of exercise tests ${ }^{6}$ two walks were performed wherever possible, with five to 10 minutes rest in between. The greater of the two distances was used for analysis. All tests were solo and therefore non-competitive. Age, height, and PEFR before and after the walk were recorded. All tests were conducted by one of two examiners (CJU or JCT).

We tested three groups of children: group 1normal children admitted for minor operations, and the healthy siblings of inpatients; group 2-'well' children with cystic fibrosis attending for routine clinical follow-up; and group 3-children with cystic fibrosis admitted for exacerbations of their chest disease, who performed the walking test before, during, and after treatment.

Statistical analysis was by linear regression with Pearson's coefficient of correlation, and Student's paired and unpaired $t$ tests.

\section{Results}

\section{GROUP 1}

Eighty nine normal children completed the test ( 32 girls and 57 boys, age range 5 to 16 years, mean $91 / 2$ years). The preponderance of boys is a reflection of their higher admission rate for minor operations. There was no difference between the boys and girls when results against height were compared using the $t$ test $(p>0.05)$. Fig 1 shows the scattergram of walking distance against height for these children with the regression line and 10th and 90th centiles. There was a strong correlation between them (Pearson correlation coefficient $0.72 ; \mathrm{p}<0.0001$ ) and also between walking distance and both age and PEFR ( $r=0.71$ and 0.67 , respectively). To look at the effect of training the first walk was compared with the second. There was a significant improvement on second testing $(\mathrm{p}<0.01)$, confirming the results of adult studies.

\section{GROUP 2}

Fifty children with cystic fibrosis took part (27 girls and 23 boys, age range 5 to 16 years, mean 11 years), and 12 of these did the test on more than one occasion. Fig 2 shows the best recorded walking distance of each individual child plotted against height, with the regression line, and 10th and 90th centiles for the normal children superimposed. There is positive correlation between walking distance and height in the children with cystic fibrosis but with greater variation (Pearson's correlation coefficient $0.56, \mathrm{p}<0 \cdot 0001$ ).

Most of these children had measurements less

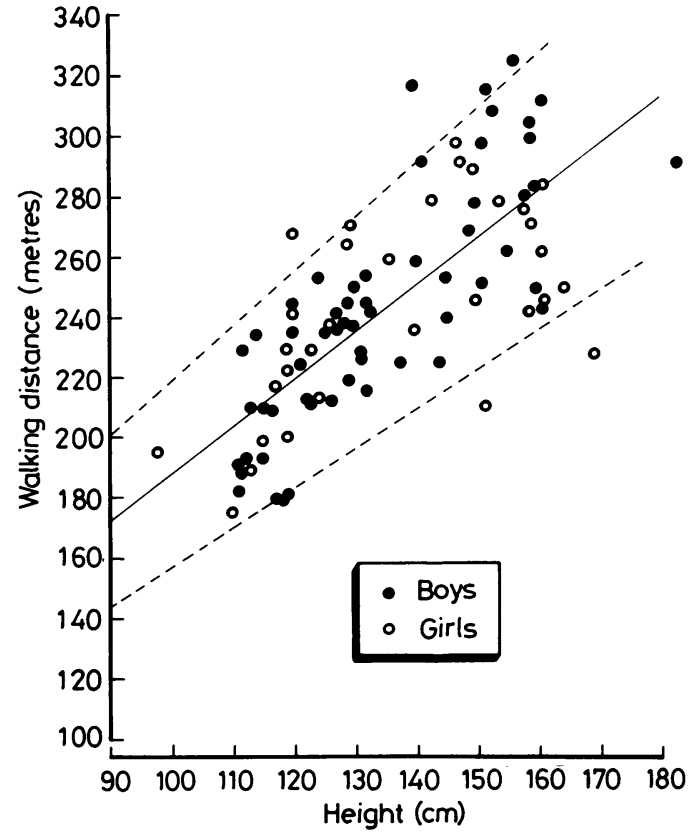

Fig 1 Two minute walking distance plotted against height in 89 normal children (- 50th centile, - - - 10th and 90th centiles).

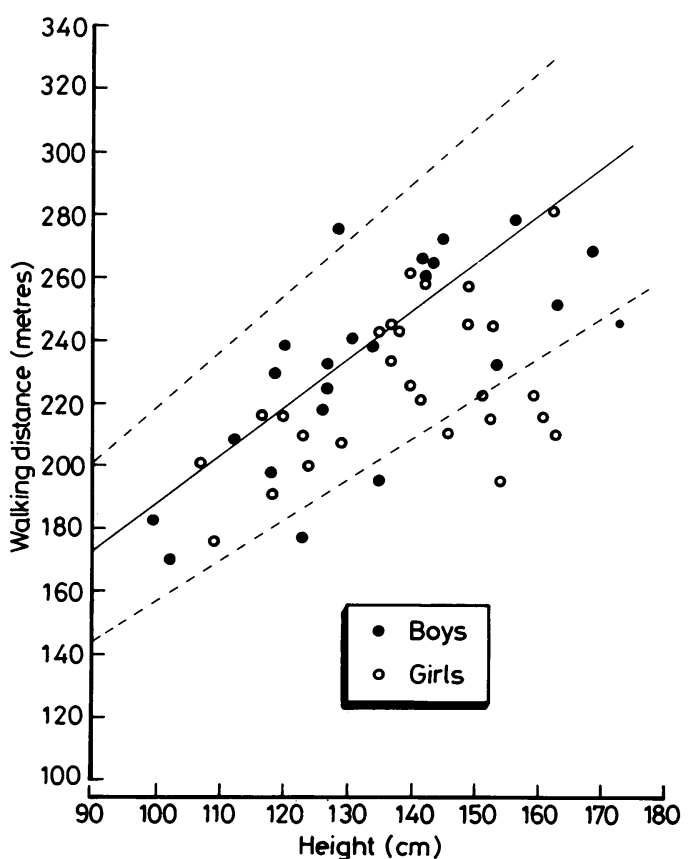

Fig 2 Two minute walking distance plotted against height in 50 children with cystic fibrosis (- -50 th centile for normal children, - - - 10th and 90 th centiles for normal children). 


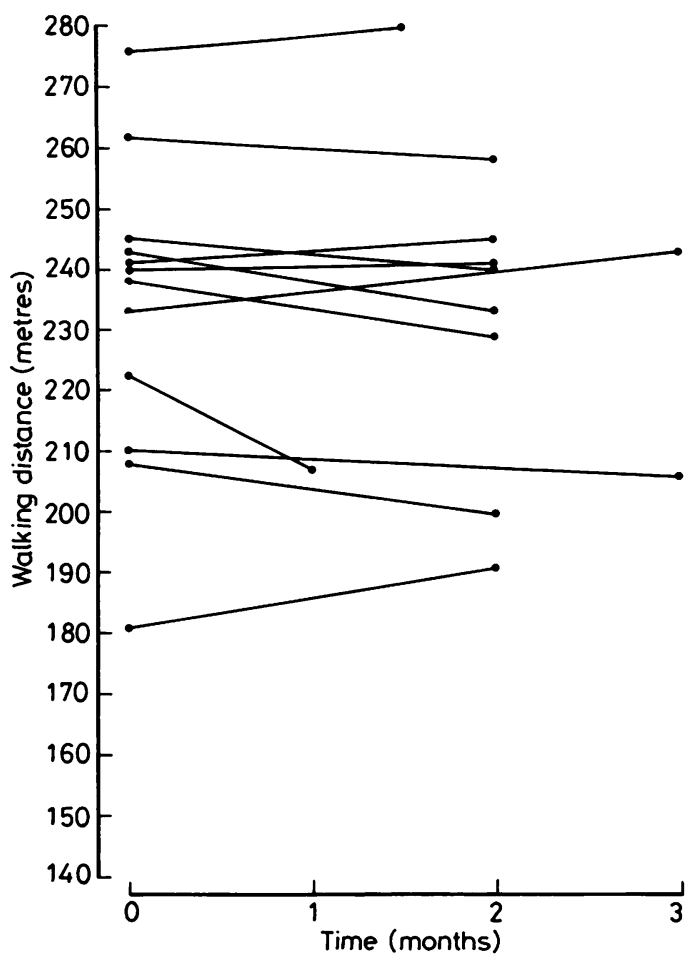

Fig 3 Two minute walking distance plotted against time in 12 children with cystic fibrosis in stable clinical condition.

than but close to the regression line for normal children (mean (SD) 93.7 (9.9)\% that of the normal group), with 10 recorded values below the tenth centile for normal children. The differences between the normal children and those with cystic fibrosis were significant $(p<0.001)$. Again there was positive correlation between walking distance and both age and PEFR ( $r=0.56$ and 0.67 , respectively).

First and second walks were again compared and, interestingly, there was no significant difference between the two in the children with cystic fibrosis. This seems to rule out a training effect in the children with cystic fibrosis, but to assess reproducibility of the walking distance further, 12 children with cystic fibrosis repeated the test one to three months after initial testing (seven girls and five boys, age range 5 to 15 years, mean 10 years). Their clinical condition was thought to be unchanged: mean (SD) PEFR $95.2(22.5) \%$ of the expected value on the first test, and $94.6(21.6) \%$ on subsequent testing (NS). The largest change was $+16 \%$. Changes in walking distance with time are shown in fig 3 . There is little variation in each child's performance: mean (SD) values were $96 \cdot 7$ (12)\% of expected on the first test, and 95.6 (12)\% on subsequent testing (NS). The largest change was $-5.9 \%$. The mean coefficient of variation calculated from all four walks for each child over two tests was just $2 \cdot 6 \%$ (range $1 \cdot 9-5 \cdot 9 \%$ ).

\section{GROUP 3}

Sixteen children with cystic fibrosis receiving inpatient treatment performed serial walks while in hospital ( 9 girls and 7 boys, age range 6 to 16 years, mean $12 \frac{1}{2}$ years; one patient was tested twice). In addition to intensive physiotherapy, all but two of these patients were treated with intravenous antibiotics for exacerbations of chest infections caused by Pseudomonas aeruginosa (one received nebulised antipseudomonal antibiotics and one an oral antibiotic for infection with Staphylococcus aureus).

The results are shown in fig 4 . There was

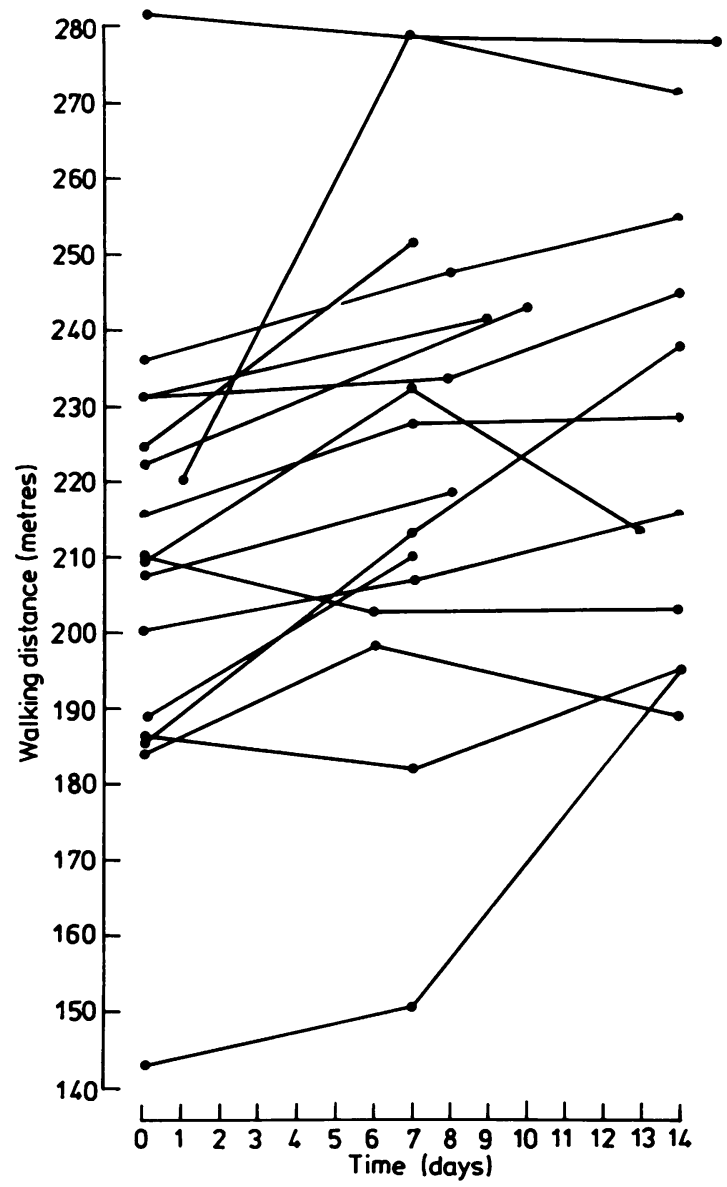

Fig 4 Two minute walking distance plotted against time during 17 courses of inpatient treatment. 
significant improvement in the percentage of expected walking distances at the end of inpatient treatment compared with the beginning $(\mathrm{p}<0.005)$. Mean (SD) values were $83.3(10.9) \%$ of expected on admission, and $90.8(11.2) \%$ at discharge. The largest change seen was $+23 \cdot 8 \%$. These changes are significantly different from those in the untreated group $(p<0.005)$ and occur over a much shorter period of time.

The PEFR in these children was $66.1(18 \cdot 3) \%$ of expected on admission and $80 \cdot 1(17 \cdot 1) \%$ at discharge. This change was also significant $(\mathrm{p}<0.005)$. The largest change was $+52 \%$. Thus we have shown significant changes in both PEFR and walking distance with treatment, these differences not being present in the untreated group. PEFR showed more short term variability in both groups, as expected from the increased bronchial lability in cystic fibrosis. ${ }^{7}$

We were worried that the walking distance would only be discriminatory in the children with the worst respiratory function. For further analysis, therefore, the treated group were split into the fittest and the least fit eight children by PEFR and walking distance. Walking distance was significantly improved after treatment in both the least fit eight children $(p<0.05)$ and the fittest eight children $(p<0.01)$. PEFR was also significantly improved with treatment in the least fit eight children $(\mathrm{p}<0 \cdot 02)$, but there was no significant difference in the fittest eight children. These results were consistent whether the group was divided by PEFR or by walking distance. This suggests that as respiratory function nears the normal range walking distance is a more discriminatory variable than PEFR, which is presumably because of the short term variability in PEFR.

\section{Discussion}

In adult patients 12 minute walking distance is a reproducible measurement that correlates with other measurements such as forced vital capacity and oxygen consumption. ${ }^{4}$ The two and six minute tests have been shown to be equally reproducible, and correlated well with the longer test. ${ }^{5}$ Rather than purely reflecting pulmonary function, such simple tests of exercise tolerance may give an indication of other factors important in day to day life such as motivation and endurance. ${ }^{8}$ We feel this is an important aspect to consider when reviewing the use of such tests. Walking is an essential part of everyday life and a familiar activity to young children. By using it in an exercise test one can gain some insight into functional disability in daily living.

We found that in general children enjoyed taking part in the test-regarding it as a game-and cooperation was good even among the younger children. The fun element in the test was, we feel, an important part in gaining this cooperation. A few teenage girls were reluctant to take part and in this group we also ran into problems with unsuitable footwear; this usually resulted in a walk in bare feet or slippers. In spite of this only two children failed to complete the test, and one would not do the second walk. On two occasions children started to jog and the test was then stopped and restarted after a rest. As the tests took place in a hospital corridor there were times when it was congested, but it rarely took longer than five minutes to clear sufficiently to perform the test reliably. Children were asked to keep to one side of the corridor, both to limit lateral movement affecting the distance achieved, and to allow passage to others. The length of corridor is important, as it needs to be short enough to allow communication from one end to the other but long enough to let children get into their stride. Thirty five metres is a similar distance to that used in adult studies. ${ }^{5}$ Encouragement was given at each turn, but not in between as this is known to affect results (at least in a six minute test). ${ }^{9}$

It is important to consider the effect that repeated tests have on results. Adult studies have shown an important effect of training, although there was no significant difference between second and third testing. ${ }^{4}{ }^{6}$ For this reason we did not feel justified in asking the children to perform more than two tests at any one sitting. Our study confirms the significant effect of training between successive walks in normal children, but not in the children with cystic fibrosis. This contrasts with the adult study of McGavin et al ${ }^{4}$ although they used a 12 minute walk and the tests were performed on different days, though one would expect that, if anything, this would make a training effect less likely. Another alternative is that our children with cystic fibrosis were tired from the first walk and the effect of training was therefore abolished. This is not supported by our results; there was no significant reduction in walking distance, nor was the walk sufficient to cause a significant drop in PEFR in any child, either with cystic fibrosis or normal. We were also careful to avoid testing children who were obviously tired; in practice the decision to embark on the second walk was left to the individual child, usually after a five to 10 minute rest.

The good reproducibility seen over one to three month periods in children with cystic fibrosis is further evidence that training is not having a great effect in this population. The variation seen is much smaller than that in adult studies using the 12 minute distance. ${ }^{10}$ It has been suggested that the increased variability in the longer test implies better discrimination, ${ }^{5}$ but no evidence for this was provided. 
Although this may be true in an adult population, we feel that a longer test in children would merely create more scope for random variation and error, not to mention boredom in the children.

Ideally we would have liked to have studied the normal children over similar time periods to those used to assess reproducibility in the children with cystic fibrosis, to confirm this reproducibility. As the study was hospital based, however, and the children were undergoing minor operations, this was not feasible. In spite of this, we would agree with Butland et al that the evidence points to a small effect of training in the two minute walk. ${ }^{5}$ We feel the problem is largely overcome by taking the longest of two successive walks.

In view of the apparently small training effect and the good reproducibility we feel that the increase in walking distance during inpatient treatment is a true reflection of the subjective improvement of the patients. This may not be purely a result of improved lung function, but also caused by improvement in general wellbeing and morale. We have also shown that this improvement is not solely in the worst affected children, and that walking distance may have an advantage over PEFR in discriminating between improvement in children with near normal lung function.

In addition to the usual measurements of lung function, we are now using the two minute walking distance to monitor changes in patients admitted with exacerbations of cystic fibrosis. We believe it gives useful objective information that may complement lung function measurements, and has the added advantage that it could be used in a district general hospital without access to a lung function laboratory. It may also supply helpful evidence in support of applications for mobility allowances.

We now intend to study children at regular intervals after discharge from hospital to see if the improvement is sustained and whether there is a fall before further exacerbations. We also intend to look at changes over a longer period and examine possible relationships with clinical scores such as the Shwachman score. ${ }^{11}$ Such a guide to 'everyday disability' may even be useful in contributing to the 'overall wellbeing' portion of the Shwachman score, which is extremely subjective.

We conclude that the two minute walking distance is a reproducible test which can be performed reliably by children as young as 5 years.

JCT is a clinical research fellow supported by the Cystic Fibrosis Research Trust.

\section{References}

1 Redding GJ, Restuccia R, Cotton EK, Brooks JG. Serial changes in pulmonary functions in children hospitalized with cystic fibrosis. Am Rev Respir Dis 1982;126:31-6.

2 Cerny FJ, Cropp GJA, Bye MR. Hospital therapy improves exercise tolerance and lung function in cystic fibrosis. Am J Dis Child 1984;138:261-5.

3 Connolly CK. Falsely high peak expiratory flow readings due to acceleration in the mouth. Br Med $J$ 1987;294:285.

${ }^{4}$ McGavin CR, Gupta SP, McHardy GJR. Twelve-minute walking test for assessing disability in chronic bronchitis. $\mathrm{Br}$ Med $\mathrm{J}$ 1976;i:822-3.

5 Butland RJA, Pang J, Gross ER, Woodcock AM, Geddes DM. Two-, six-, and 12-minute walking tests in respiratory disease. Br Med J 1982;284:1607-8.

6 Swinburn CR, Wakefield JM, Jones PW. Performance, ventilation and oxygen consumption in three different types of exercise test in patients with chronic obstructive lung disease. Thorax 1985;40:581-6.

7 Day G, Mearns MB. Bronchial lability in cystic fibrosis. Arch Dis Child 1973;48:355-9.

${ }^{8}$ Morgan AD, Peck DF, Buchanan DR, McHardy GJR. Effect of attitude and beliefs on exercise tolerance in chronic bronchitis. Br Med J 1983;286:171-3.

9 Guyatt GH, Pugsley SO, Sullivan MJ, et al. Effect of encouragement on walking test performance. Thorax 1984;39:818-22.

${ }^{10}$ Mungall IPF, Hainsworth R. Assessment of respiratory function in patients with chronic obstructive airways disease. Thorax 1979;34:254-8.

11 Shwachman H, Kulcycki LL. Long study of one hundred and five patients with cystic fibrosis. Am J Dis Child 1958;96:6-15.

Correspondence to Dr C J Upton, Department of Paediatrics, City Hospital, Hucknall Road, Nottingham NG5 1PB.

Accepted 20 June 1988 